\title{
Gemälde der Gegenwartskunst keine abnutzbaren Wirtschaftsgüter
}

Finanzgericht Berlin-Brandenburg, Urteil vom 06. Dezember 2007 - 1 K 7418/04 B

\section{Gemälde anerkannter Meister der Gegenwartskunst stellen keine abnutzbaren Wirtschaftsgüter im Sinne des \$ 6 b EStG a.F. dar. In der Regel kommt weder eine wirtschaftliche noch eine technische Abnutzung in Betracht. (Leitsatz d. Redaktion)}

\section{$[\ldots]$}

\section{Tatbestand}

- Die Beteiligten streiten um die Bildung einer Rücklage aus der Veräußerung zweier Gemälde.

Die Klägerin betrieb im Streitjahr neben einem gewerblichen Grundstückshandel einen Kunsthandel. Sie veräußerte in diesem Jahr zwei zu ihrem Anlagevermögen gehörende, 1977 bzw. 1987 angeschaffte Gemälde mit einem Gewinn in Höhe von insgesamt 1.205.499,07 DM. Die Klägerin erklärte im April 1999 in ihrer Feststellungserklärung 1996 einen Verlust in Höhe von 7.928.099,00 DM. Dabei berücksichtigte sie eine Rücklage nach § 6 b Einkommensteuergesetz -EStG- in Höhe des gesamten Gewinns aus der Veräußerung der Gemälde. Der Beklagte stellte die Einkünfte aus Gewerbebetrieb mit unter dem Vorbehalt der Nachprüfung ergangenem Bescheid vom 20. Mai 1999 antragsgemäß fest.

Der Beklagte führte für die Jahre 1994 bis 1996 eine Betriebsprüfung bei der Klägerin durch. Der Betriebsprüfer gelangte zu der Überzeugung, die Rücklage könne für Kunstwerke nicht gebildet werden. Die Bildung einer Rücklage setze voraus, dass das veräußerte Wirtschaftsgut abnutzbar gewesen sei. Gemälde unterlägen weder einer technischen noch einer wirtschaftlichen Abnutzung. Der Beklagte schloss sich den Feststellungen des Betriebsprüfers an und stellte unter Aufhebung des Vorbehalts der Nachprüfung mit Änderungsbescheid vom 14. März 2002 die Einkünfte aus Gewerbebetrieb 1996 auf -8.403.097,91 DM fest. Die Rücklage aus dem Gemäldeverkauf fand keine Berücksichtigung mehr. Die Klägerin legte hiergegen am 22. März 2002 Einspruch ein, mit dem sie die Berücksichtigung einer Rücklage in Höhe von 603.000 DM begehrte. Sie machte geltend, auch Gemälde unterlägen einer technischen Abnutzung, selbst wenn diese fachmännisch behandelt würden. Der Beklagte wies den Einspruch mit Einspruchsentscheidung vom 25. August 2004 zurück. Die Rücklage dürfe nicht gebildet werden. Gemälde unterlägen keiner wirtschaftlichen oder technischen Abnutzung. Abnutzbar seien nur solche Gegenstände, die einem wirtschaftlichen oder technischen Wertverzehr ausgesetzt seien. Allerdings komme eine technische Abnutzung auch ohne eine wirtschaftliche Abnutzung in Betracht. Das sei der Fall, wenn ein körperlicher Verschleiß durch Gebrauch eintrete. Ein solcher Fall sei nicht gegeben. Die Zeiträume, in denen ein Gemälde technisch abnutze, seien so lang, dass dies aus steuerlicher Sicht vernachlässigt werden könne und ein Fall der §§ 6, 7 EStG nicht gegeben sei.

Die Klägerin macht geltend, bei den veräußerten Gemälden handele sich um abnutzbare Wirtschaftsgüter im Sinne des § 6b EStG.
Die Gemälde unterlägen einer langsamen technischen Abnutzung. Nichts anderes ergebe sich aus der vom Beklagten herangezogenen Rechtsprechung des Bundesfinanzhofs. Dort werde bereits festgestellt, dass eine technische Abnutzung auch bei Kunstwerken vorhanden sei. Diese sei lediglich so geringfügig, dass sie im Rahmen der AfA steuerlich vernachlässigt werden dürfe. Die Rechtsprechung betreffe mithin nur die Frage, ob Abschreibungen geltend gemacht werden können. Sie sage nichts darüber aus, ob eine Rücklage gebildet werden dürfe. Es liege auf der Hand, dass die Auslegung des Begriffs des abnutzbaren Wirtschaftsguts in $\S 6 \mathrm{~b}$ EStG zu einem anderen Ergebnis führen müsse. § $6 \mathrm{~b} \mathrm{EStG}$ verfolge das Ziel, aus betriebswirtschaftlicher oder volkswirtschaftlicher Sicht sinnvolle Veräußerungen von langlebigen Wirtschaftsgütern des Anlagevermögens, die erhebliche stille Reserven bergen könnten, nicht dadurch zu verhindern, dass aufgedeckte stille Reserven sofort und in voller Höhe nach dem allgemeinen Tarif versteuert werden müssten. Insofern müsse $\S 6 \mathrm{~b}$ EStG bei einem Wirtschaftsgut wie dem vorliegenden erst recht angewendet werden, weil hierin besonders hohe stille Reserven lägen. Zudem gehe auch der Bundesfinanzhof davon aus, dass Gemälde abnutzbare Wirtschaftsgüter seien, die lediglich nicht abzuschreiben seien. Gemälde unterschieden sich demnach von anderen Wirtschaftsgütern nur dadurch, dass sich die Abnutzung über einen vergleichsweise langen Zeitraum weit jenseits des Mindestzeitraums von 25 Jahren vollziehe. Im Übrigen sei die Ansicht des Bundesfinanzhofs, dass ein Gemälde im Rahmen der Abschreibungen nicht zu berücksichtigen sei, ohnehin nicht unbestritten. Schließlich müsse berücksichtigt werden, dass die begrenzte Nutzbarkeit eines Gemäldes allgemein auch durch äußere Umstände und Einflüsse entstehen könne. Es komme nicht darauf an, auf welcher Ursache die zeitliche Nutzungsbeschränkung beruhe.

Der Beklagte macht geltend, § 6b EStG knüpfe mit der Verwendung des Begriffs des abnutzbaren Wirtschaftsgutes an die Regelungen in §§ 6, 7 EStG an und setze voraus, dass die Nutzungsdauer des Wirtschaftsguts bestimmbar sei. Das sei vorliegend nicht der Fall. Im Übrigen bestehe auch kein Grund, den Begriff des abnutzbaren Wirtschaftsgutes in $\S 6 \mathrm{~b}$ EStG anders und weiter auszulegen als in $\S \S 6,7$ EStG. Anderenfalls sei die Beschränkung des $\S 6 \mathrm{~b}$ EStG auf abnutzbare Wirtschaftsgüter überflüssig. Es dürfe im Rahmen des § $6 \mathrm{~b}$ EStG auch nicht maßgeblich darauf abgestellt werden, dass das Wirtschaftsgut jedenfalls langlebiger als 25 Jahre sei. (Sachverhalt von der Redaktion gekürzt.)

\section{Entscheidungsgründe}

Die Klage hat keinen Erfolg. Der Bescheid des Beklagten vom 14 März 2002 ist nicht unter Aufhebung der Einspruchsentschei- 
dung vom 25. August 2004 abzuändern, denn die Klägerin hat keinen Anspruch auf die Bildung der begehrten Rücklage, § 100 Abs. 1 Finanzgerichtsordnung FGO.

Die tatbestandlichen Voraussetzungen für die Bildung der Rücklage nach $\S 6$ b Abs. 3 EStG lagen nicht vor. Nach $\S 6$ b Abs. 3 EStG in der für das Streitjahr maßgeblichen Fassung (a.F.) können Steuerpflichtige unter den weiteren Voraussetzungen des $\S 6$ b Abs. 4 EStG im Wirtschaftsjahr der Veräußerung eines abnutzbaren beweglichen Wirtschaftsgutes mit einer betriebsgewöhnlichen Nutzungsdauer von mindestens 25 Jahren eine den steuerlichen Gewinn mindernde Rücklage bilden. Die von der Klägerin veräußerten Gemälde sind keine abnutzbaren Wirtschaftsgüter, denn sie sind im steuerlichen Sinne weder wirtschaftlich noch technisch abnutzbar.

Der in $\S 6$ b EStG a.F. verwendete Begriff des abnutzbaren beweglichen Wirtschaftsgutes entspricht in seinem rechtlichen Gehalt den in $\S 6$ Abs. 1 Nr. 1 bzw. § 7 EStG verwendeten identischen Begriffen (so auch Heuer in: Hermann/Heuer/Raupach, EStG-KStG, § 6b EStG, Rn. 130; Thiel, Übertragung stiller Reserven, 1965, S. 42; Heger in: Kirchhof/ Söhn/Mellinghof, EStGKommentar, § 6b Anm. B 45). Dafür spricht zunächst die Entstehungsgeschichte der 1964 erstmals ins Einkommensteuergesetz aufgenommenen Vorschrift, die sich terminologisch an die damals bereits bestehenden Vorschriften in $\S \S 6,7$ EStG anlehnt. Aus systematischer Sicht deutet das bereits darauf hin, dass die in benachbarten Vorschriften enthaltenen übereinstimmenden Begriffe auch in gleicher Weise zu verstehen sind. Dies wird auch dadurch unterstrichen, dass bereits der amtlichen Begründung des Gesetzentwurfs zu entnehmen ist, dass neben Grundstücken vor allem „abschreibungsfähige Anlagegüter" in den Genuss der Begünstigungsregelung kommen sollten (vgl. BT-Drucks. IV/2400 S. 46 Ziff. III.1.). Demnach knüpft der Gesetzgeber - jenseits der ausdrücklich geregelten Behandlung von Grund und Boden - für die durch § 6b EStG a.F. vorgesehene Steuerbegünstigung gerade daran an, dass das bewegliche Wirtschaftsgut abgeschrieben werden kann. Das belegt, dass der Begriff der abnutzbaren beweglichen Wirtschaftsgüter in § 6b EStG nicht anders als in $\S \S 6,7$ EStG verstanden werden darf. Anderes ergibt sich nicht aus Sinn und Zweck der Vorschrift. Allerdings verfolgt der Gesetzgeber mit § 6b EStG das Ziel, wie die Klägerin zu Recht bemerkt, ökonomisch erwünschte Anpassungsprozesse im Wirtschaftsleben nicht durch steuerliche Bestimmungen zu behindern. Insbesondere sollte durch $\S 6$ b EStG die Möglichkeit eröffnet werden, die bei der Veräußerung langlebiger Güter des Anlagevermögens oftmals entstehenden hohen Veräußerungsgewinne im Interesse der Modernisierung der Betriebe nicht sofort und in voller Höhe den Ertragssteuern zu unterwerfen (vgl. BT-Drucks. IV/2400 S. 62). Das gibt aber nichts für die hier im Vordergrund stehende Frage her, in welcher Weise der Begriff „abnutzbares bewegliches Wirtschaftsgut" auszulegen ist. Zwar mögen gerade auch Kunstgegenstände typischerweise - und so auch im vorliegenden Fall - über die Jahre wesentliche Wertsteigerungen erfahren, die im Falle einer Veräußerung zu einer aus steuerlichen Gründen unerwünschten Aufdeckung stiller
Reserven führen kann. Dem kann jedoch nicht in der Weise begegnet werden, dass dem gesetzlichen Abgrenzungskriterium der Abnutzbarkeit jede Trennschärfe genommen wird, indem jedweder langwierige natürliche Alterungsprozess, der nicht zu AfA berechtigen würde, zur steuerlichen Begünstigung nach § $6 \mathrm{~b}$ EStG führen würde. Dabei kann zunächst nicht außer Acht gelassen werden, dass auch andere nicht abnutzbare bewegliche Wirtschaftsgüter, wie etwa Edelmetalle oder Edelsteine, häufig besonders große stille Reserven bergen, der Gesetzgeber sich aber dennoch dafür entschieden hat, bei einer Veräußerung derartiger Wirtschaftsgüter die Ermäßigungsmöglichkeiten des $\S 6 \mathrm{~b}$ a.F. EStG nicht zu gewähren. Zum anderen würde eine derart weit reichende Auslegung nicht mit der Grundkonzeption der Vorschrift in Einklang stehen. Tatsächlich soll dem Steuerpflichtigen durch $\S 6 \mathrm{~b}$ EStG regelmäßig nur eine Steuerstundung gewährt werden, die grundsätzlich über die (gekürzte) AfA der innerhalb eines bestimmten Zeitraums anzuschaffenden beweglichen Wirtschaftsgüter abgebaut wird (vgl. § 6b Abs. 1 Satz 2 EStG a.F.). Würde die Vorschrift aber auch - außerhalb von Grund und Boden - im Sinne der AfA-Vorschriften nicht abnutzbare Wirtschaftsgüter erfassen, könnte der Stundungseffekt nicht ratierlich abgebaut werden und käme es unter Umständen auf Dauer zu einer grundsätzlich nicht beabsichtigten Steuerermäßigung. Anders läge es nur dann, wenn der Begriff des abnutzbaren Wirtschaftsgutes in $\S 6$ b Abs. 1 Satz 2 EStG a.F. anders - nämlich im Sinne des § 7 EStG - auszulegen wäre als derselbe Begriff in § 6b Abs. 1 Satz 1 EStG a.F. Dafür spricht erkennbar nichts. Kann § $6 \mathrm{~b}$ EStG a.F. hinsichtlich des Begriffs „abnutzbares Wirtschaftsgut" mithin nicht anders als $\S \S 6,7$ EStG ausgelegt werden, findet dies seine Bestätigung auch darin, dass der Bundesfinanzhof das weitere Tatbestandsmerkmal der betriebsgewöhnlichen Nutzungsdauer ebenfalls dahin ausgelegt hat, dass dieser Begriff den zu § 7 EStG entwickelten Grundsätzen entspricht (vgl. Urteil vom 19. Mai 1976 - R 164/74, BStBI II 1977,60).

Ausgehend von diesen Grundsätzen hat der Beklagte die Bildung der Rücklage zu Recht nicht zugelassen, denn bei den beiden veräußerten Gemälden handelt es sich nicht um abnutzbare Wirtschaftsgüter im Sinne des § 6b EStG a.F. Bei den Gemälden handelt es sich um wertvolle Werke zweier anerkannter Meister der Gegenwartskunst, die - wie zwischen den Beteiligten unstreitig ist - wirtschaftlicher Abnutzung nicht unterliegen, handelt es sich doch nicht um schlichte Gebrauchskunst (vgl. zur Abgrenzung: BFH, Urteile vom 23. April 1965 - VI 327/64 U, BStBI III 1965, 382; vom 2. Dezember 1977 - III R 58/75, BStBI II 1978, 164;Beschluss vom 2. September 1988 - III B 31/88, BFH/NV $1989,129)$. Aber auch eine technische Abnutzung im Sinne des $\S 6 \mathrm{~b} \mathrm{EStG}$ a.F. kommt nicht in Betracht, denn die bei sachgerecht behandelten Gemälden im Wesentlichen durch Umwelteinflüsse bedingte Abnutzung ist derart gering, dass sie steuerlich auBer Betracht bleiben muss (vgl. BFH Urteile vom 2. Dezember 1977 - III R 58/75 a.a.O.; vom 9. August 1989 - X R 131133/ 87, BStBI II 1990, 50). [...] 